\title{
Analysis of the Lottery Process for Liberal Arts Class Placement at the University of Hyogo using the PDCA Cycle
}

\author{
Yoshihiko Shoji *, Yoshihiro Kokubo *
}

\begin{abstract}
The section for Institutional Research was renewed in 2015 at the University of Hyogo. One of its first projects was reforming the rules regarding the placement for liberal arts classes. The initial mission was to create a new schedule for the guidance, application, class placement lottery, and registration by new students. This reform process was crucial for the section because the more serious future challenge is not data collection and analysis, but how to improve the university. Herein we explain several results from our first project and how they lead to improvements using the PDCA (Plan-Do-Check-Act) cycle.
\end{abstract}

Keywords: Institutional Research, PDCA Cycle, University Organization

\section{Introduction}

The section for Institutional Research (IR), which is the planning section in the Institute of General Education, was renewed at the University of Hyogo in April 2015. The University of Hyogo [1] comprises three prefectural educational institutes: the Kobe University of Commerce, Himeji Institute of Technology, and the College of Nursing Arts and Science. Each has its own campus and traditions. Historically, the Office for Planning was in charge of planning, but was ineffective because each institute has its own system for planning and improvement. However, the present action based on each institute is insufficient to comply with the University Reform Action Plan [2] by the Ministry of Education, Culture, Sports, Science and Technology of Japan. To re-boot the Office of Planning, the Vice Director of the Institute of General Education, who also holds the post of professor at the School of Human Science and Environment, became the head in 2015. In April 2016 two associate professors joined the office as new members while retaining their posts in their original sections. The authors, who are the new members, have been engaged in preparing for educational reform.

One of the initial missions was to reform the liberal arts course selection of new students by adjusting the schedule for guidance, application, class placement lottery, and registration. The lottery takes place in April only at the western area, which had been the Himeji Institute of Technology. This process affects roughly 740 students or about $60 \%$ of the university freshmen.

* University of Hyogo, Hyogo, Japan 
If too many students wish to enroll in a specific course, registration is via a lottery. The main issue with the lottery process was that it took over two weeks, and students could not attend the class until the lottery results were announced.

Solving the initial problem in 2015 revealed other issues. Our analysis of the course placement process was used to refine the process in 2016. These efforts have resulted in an annual improvement cycle, which can be explained as the well-known PDCA (Plan-Do-Check-Act) cycle.

PDCA (Plan-Do-Check-Act) is an iterative four-step management method used to control and continuously improve processes $[3,4,5]$. Figure 1 overviews the cycle, which is explained in detail in section II. The PDCA cycle was made popular by W. E. Deming, who developed the idea in his lectures held at the Mt. Hakone Conference Center in August 1950 [6, 7]. It is said that a number of Japanese manufacturers have applied his techniques and experienced high levels of quality and productivity. To date, the PDCA cycle has been used as an excellent foundation for improvement in various fields, including education and university management $[8,9,10,11,12]$ and Institutional Research [13]. Below we explain how our IR section applied the PDCA cycle to identify factors crucial for successful improvements.

\section{PDCA Cycle}

\subsection{PDCA Cycle of the Lottery Process for Class Placement}

The two fundamentals of the PDCA cycle are the iteration and the separation of each phase. Our cycle has four phases.

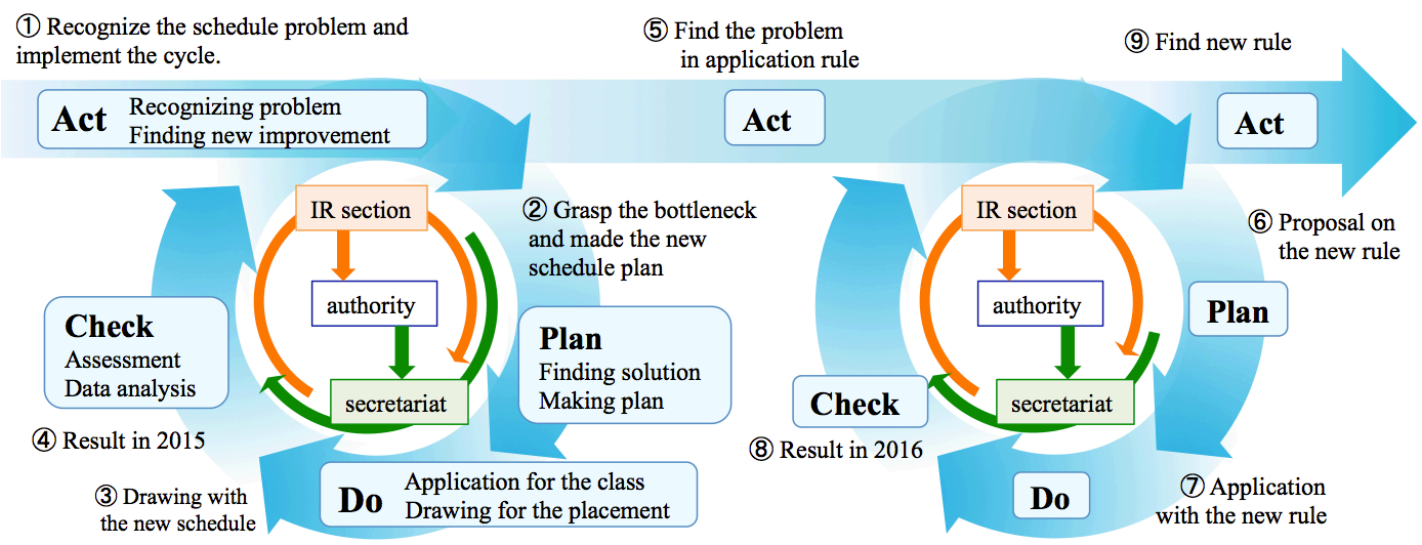

Figure 1: PDCA Cycle for the lottery for class placement of liberal arts.

Plan: Develop a plan or process to achieve the required improvement and obtain approval to execute the plan.

Do: Execute the plan and collect data from students' applications and the lottery results. 
Check: Identify weaknesses in the process based on the data.

Act: Identify new problems and set goals for the next cycle based on the analysis.

Figure 1 shows the work in each phase of our cycle. We started from the Act, as indicated by circle number 1, and are now (November 2016) in the third Act phase indicated by circle number 9 . The narrow circular arcs show the groups functioning in each phase.

\subsection{Initial Cycle in 2015}

The stating point of the cycle, the Act phase, was to initiate the cycle to reduce the time required for new students to register for courses. Staff members were aware of the issue but a plan of action to address the issue had not been tested. Figure 2 shows the organization for general education, which includes the liberal arts program in the western area. Prior to conducting a trial of our action, we discussed our ideas with the Chairman of the Committee in the Western Area and obtained his permission. Although we did not have a clear plan, we had ideas to shorten the scheduling process from two weeks to a few days.

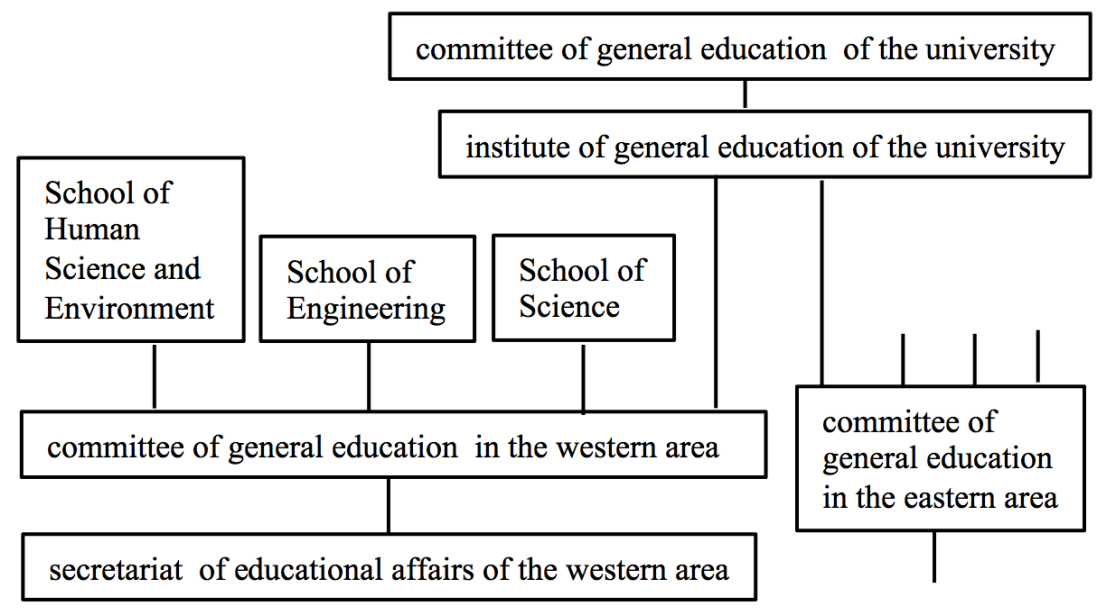

Figure 2: Organization for general education.

In the next Plan phase, discussions with the secretariats of the Educational Office revealed that the bottleneck in the scheduling process was due to the unstable OCR (optical character recognition) system, which was used to read the characters in the application forms. The secretariats had to spend days fixing the many readout errors. Table 1 shows the old and the new schedule. We proposed two options to address the issue. The first was to use a free bubble sheet form. The second was to have the system developer adjust the OCR system. Ultimately, we adopted the improved OCR system because it was easier to transfer the data to the registration system. 
We also proposed to separate the applications for the liberal arts program by semester, and accept spring semester applications for liberal arts first. Except for the spring semester, this eliminated a rapid lottery, allowing students more time to make course selections. Additionally, the spring semester results could be announced in one day before the semester began. The Committee of General Education in the Western Area approved our new plan.

Table 1: Time Tables of the Registration Process for Liberal Arts Courses in 2014 and 2015 .

\begin{tabular}{|c|c|c|}
\hline $\begin{array}{l}\text { Date of } \\
\text { April }\end{array}$ & Year 2014 & Year 2015 \\
\hline 2nd & \multicolumn{2}{|c|}{ Distribution of documents for the application } \\
\hline \multirow{2}{*}{$3 \mathrm{rd}$} & Guidance & Guidance; \\
\hline & & $\begin{array}{l}\text { Application submission for the liberal } \\
\text { arts classes for the spring semester }\end{array}$ \\
\hline 4th & Entrance ceremony & (Saturday) \\
\hline 5 th & (Saturday) & (Sunday) \\
\hline \multirow[b]{2}{*}{ 6th } & (Sunday) & Entrance ceremony; \\
\hline & & $\begin{array}{l}\text { Announcement of the spring semester } \\
\text { lottery results }\end{array}$ \\
\hline 7th & First day of classes & First day of classes \\
\hline \multicolumn{3}{|l|}{ 8th } \\
\hline 9th & & $\begin{array}{l}\text { Application submission for the other } \\
\text { subjects }\end{array}$ \\
\hline 10th & $\begin{array}{l}\text { Application submission for all sub- } \\
\text { jects for the whole year }\end{array}$ & \\
\hline \multicolumn{3}{|l|}{ 11-17th } \\
\hline 18th & Announcement of the lottery results & (Saturday) \\
\hline
\end{tabular}

The secretariats implemented the Do phase. Due to an unforeseen issue in the placement of students' ids, one day was lost. However, the announcement of the lottery results occurred on schedule.

In the Check phase, we analyzed the application and registration data. This was the first time application statistics were analyzed. Additionally, we collected data at the end of the semester to determine the correlation between grades and individual preferences in the lottery process. Section III explains some of the results.

\subsection{The Second and Future Cycles}


The second Act phase set a new goal based on the findings in the first Check phase. The new scheduling process had a side effect; it became possible for students to make choices for the fall semester knowing the results of the spring semester. Utilizing this merit, we strived to reduce the number of students with the worst luck (not receiving their top choice in several courses) in the lottery process. Section III describes the plan and the necessary changes to this application rules.

In the Plan phase we proposed a new application rule for fall classes. The application data in 2015 were used to estimate number of "saved" students. This proposal was explained at the meeting in 2016 and approved by the committee. We are currently in the Act phase for 2017.

For 2017 the university is planning a drastic change in the general education curriculum. Its aim is to introduce a new education program, which includes a local area study, a disaster reduction, and a global education. In the next Act phase (in 2017), we hope that the application data in 2015 and 2016, which provide information about the lectures desired by students, will be valuable when designing the new curriculum.

\section{Data Analysis in May 2015}

\subsection{Application Statistics}

Table 2 shows the number of subjects by category for two semesters. The categories are 'social science', which meets during the first period on Mondays, 'cultural science', which meets during the third period on Mondays, and 'introduction to research', which meets during the first period on Wednesdays. Students are required to submit five courses in order of preference for each category. One additional category, 'natural science', which meets during the first period of Tuesdays, has three subjects, but is only available for students in the School of Engineering. Figure 3 (a) shows the number of applications with first preference by course as well as the capacity of each course in 2015. Of the 55 courses, 13 had more new students who listed the course as their first preference than the registration capacity for freshmen. Of the available freshman seats, five were held for those repeating the course. Figure 4 shows the lottery results and the order preference rates of the students. Roughly $2 / 3$ of all of applications received their first preference. Very few students had to register for their fifth preference; the exception was that $5 \%$ of students received their fifth preference in the cultural science category in the fall semester. In any category, no more than four classes reached the capacity limit. Only two students were unable to register for a course on their preference list because they did not follow directions and submitted less than five courses.

Table 2: Categories of Liberal Arts Subjects.

\begin{tabular}{|c|c|c|c|c|c|c|}
\hline \multirow{2}{*}{$\begin{array}{l}\text { Se- } \\
\text { mester }\end{array}$} & \multirow[t]{2}{*}{ Category } & \multirow{2}{*}{$\begin{array}{l}\text { Period, } \\
\text { Day of } \\
\text { the week }\end{array}$} & \multicolumn{2}{|c|}{ Class Capacity } & Number & of Sub- \\
\hline & & & Whole & $\begin{array}{l}\text { For } \\
\text { Fresh } \\
\text { men }\end{array}$ & Whole & $\begin{array}{l}\text { Capaci- } \\
\text { ty Filled } \\
\left(\begin{array}{r}1 \mathrm{st} \\
\end{array}\right.\end{array}$ \\
\hline
\end{tabular}


Preference)

\begin{tabular}{lllllll}
\hline \hline \multirow{2}{*}{ Spring } & Social Science & 1st, Mon. & 1135 & 1090 & 9 & $2(2)$ \\
& Cultural Science & 5th, Mon. & 880 & 845 & 8 & $4(2)$ \\
& Introduction to Research & 1st, Wed. & 1275 & 1225 & 10 & $2(2)$ \\
& Natural Science ${ }^{*}$ & 1 st, Tue. & 390 & 380 & 3 & $1(1)$ \\
& Social Science & 1 st, Mon. & 935 & 900 & 7 & $4(2)$ \\
& Cultural Science & 5th, Mon. & 930 & 895 & 8 & $4(3)$ \\
& Introduction to Research & 1st, Wed. & 1055 & 1005 & 10 & $4(1)$ \\
\hline
\end{tabular}

a. Subjects only for the School of Engineering

Figure 3 (b) shows the number of students registered by course. It was interesting that the course occupancy can be divided into three groups: courses that were over $90 \%$ of capacity, courses between $40-80 \%$ of capacity, and courses less than $20 \%$ of capacity (two courses). The percentage of course capacity can help with room assignments; classes with a small number of

- Social Sci. (spring)

- Cultural Sci. (spring)

- Natural Sci. (spring)

- Intro. to Reaearch (spring)

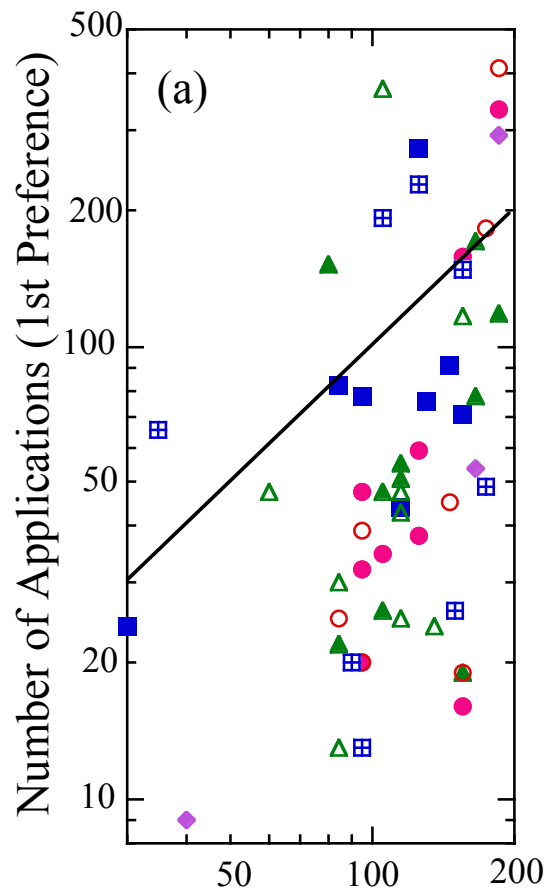

Capacity of Class
- Social Sci. (fall)

$\boxplus$ Cultural Sci. (fall)

$\Delta$ Intro. to Reaearch (Fall)

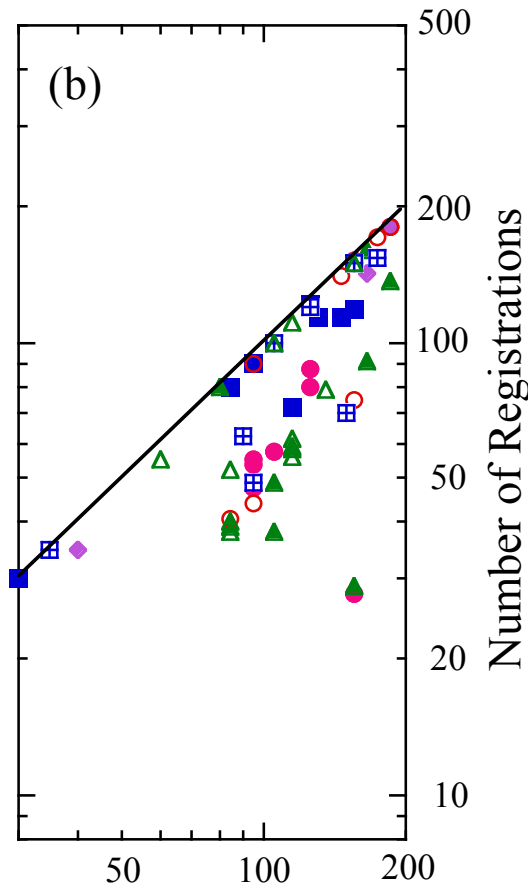

Figure 3: (a) Number of applications with the 1st preference by course and (b) Number of registered students by course in 2015 . 
students can be taught in smaller rooms.

Figure 5 shows the average of preference order for courses registered at capacity. As expected, the average of the order of preference was worse for courses with a smaller maximum student capacity. To reduce students' frustration due to perceived bad luck in course assignments, increasing the capacity of the fall semester to at least 1000 students would help. 


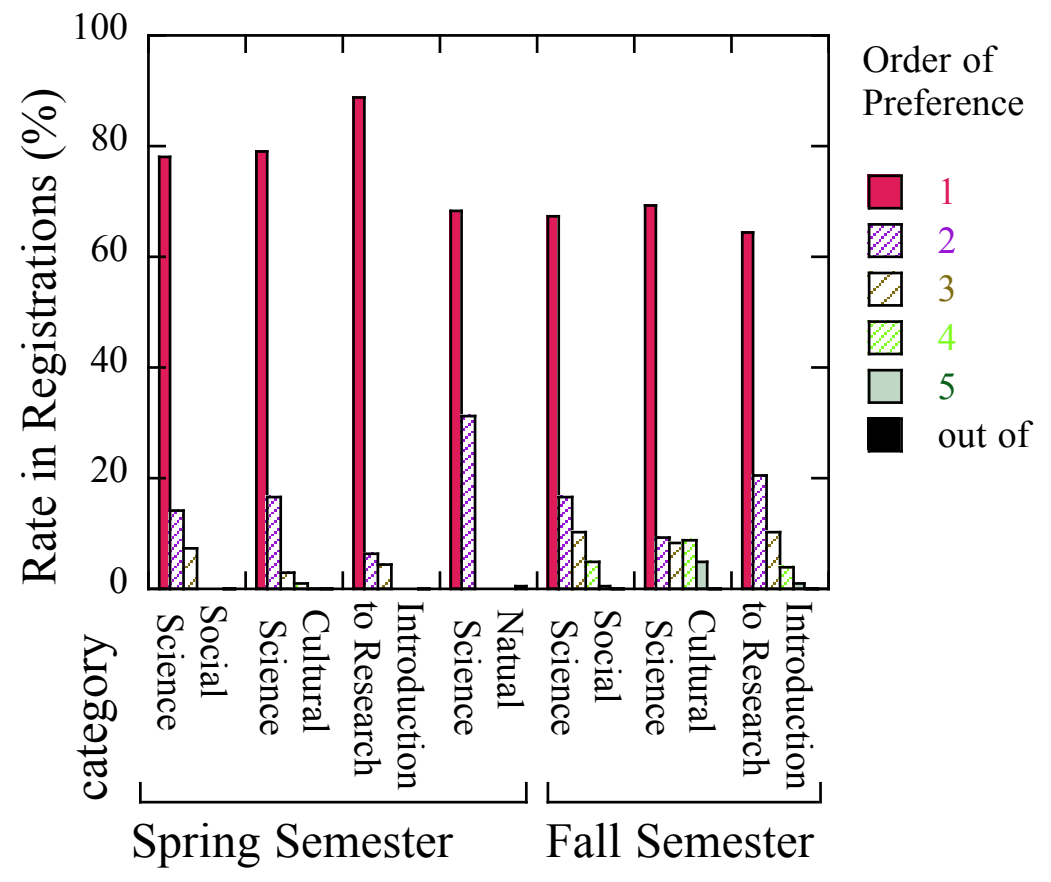

Figure 4: Freshman registration rate by preference order in 2015.

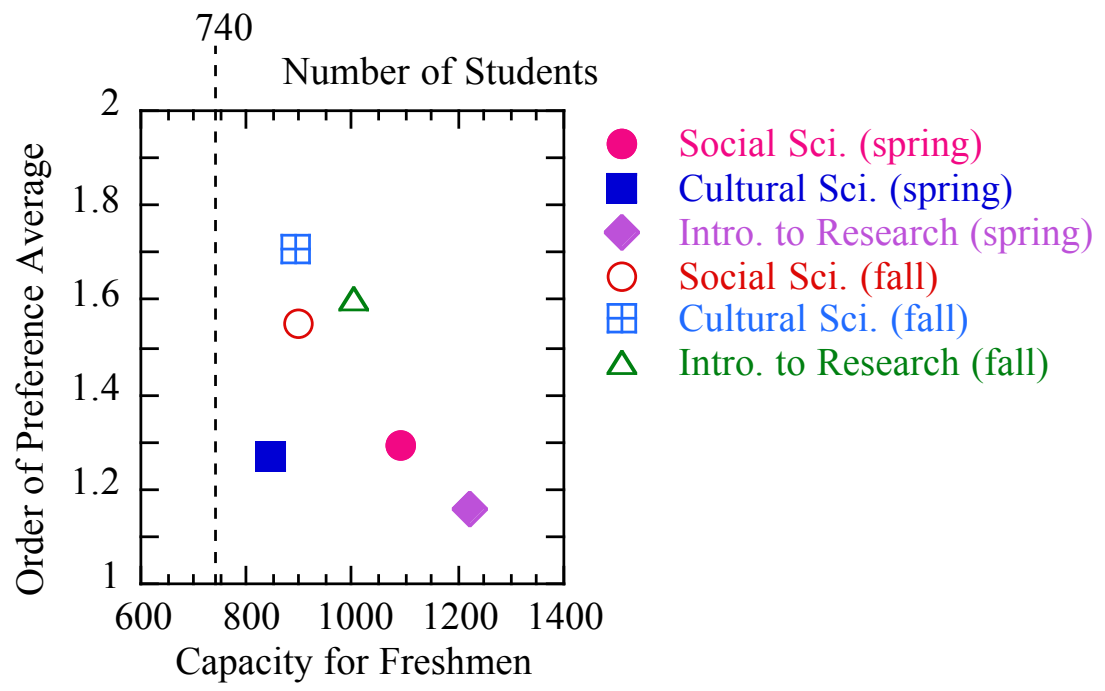

Figure 5: Average preference order of registered courses and the capacity of the category.

\subsection{Popular Classes}

The anticipated change in 2015 did not occur. Three subjects had two classes (one in the spring and another in the fall semester) that still had more applicants than class capacity. The most 
popular subject, The Constitution of Japan, is unique because all students who want to become high school teachers must take this course. In 2014, students had to apply for the both semesters to minimize the risk in the lottery. However, in 2015 students who successfully registered for the spring class did not have to apply to the fall class. We expected fewer applicants in the fall, but we were wrong.

Table 3 shows the number applicants that listed the three most popular courses as the first preference in 2015. For all three courses, students who registered for the spring class also wanted to register for the fall class. The problem is that the double registrations prevent other students from taking these courses.

Consequently, a new application rule was proposed for the fall semester in 2016. The new rule prevents students who registered for the spring class from applying for the fall class as their first preference. Table 3 shows the number of students who applied for the aforementioned three subjects in 2015. With the new rule, most students who applied for the most popular courses as their first preference in both semesters would get registration into at least one class.

Table 3: Numbers of applications listing one of three most popular courses as their first preference and the registration outcomes in 2015.

\begin{tabular}{llll}
\cline { 2 - 3 } Subjects & $\begin{array}{l}\text { The } \begin{array}{c}\text { Con- } \\
\text { stitution } \\
\text { Japan }\end{array} \\
\text { of Psychology }\end{array}$ & $\begin{array}{l}\text { Carrier } \\
\text { Planning }\end{array}$ \\
\hline \hline $\begin{array}{l}\text { Number of applications listing one of three most } \\
\text { popular courses as their first preference but did }\end{array}$ & 75 & 37 & 41 \\
not register & & & \\
$\begin{array}{l}\text { Number of applications listing one of three most } \\
\text { popular courses as their first preference and } \\
\text { registered for both classes }\end{array}$ & 48 & 20 & 13 \\
$\begin{array}{l}\text { Number of applications that did not apply for } \\
\text { the spring course but registered for the fall class }\end{array}$ & 92 & 58 & 72 \\
\hline
\end{tabular}

Figure 6 shows the status of the registration for The Constitution of Japan in 2016. No students were allowed to double register. However, 56 students, who did not apply for the spring class as their first preference, registered for the fall class because the new rule was misunderstood by the secretariats. The data also showed that even if the new rule were applied correctly, 61 students who applied for the both class as their first preference would not have registered. 


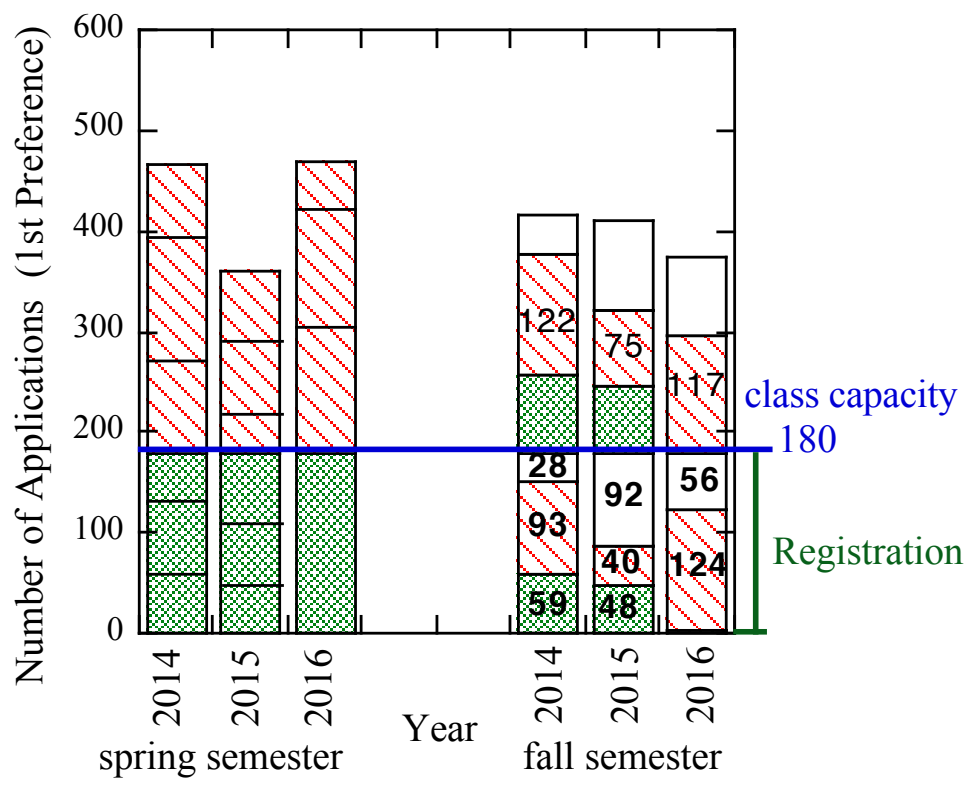

Figure 6: Number of students with The Constitution of Japan as their first preference. Dark boxes indicate students who registered for the spring semester class. Shaded boxes indicate students who applied for the spring class as the first preference and could not register. Clear

boxes indicate students who did not apply for the spring class as the first preference.

\subsection{Biased Decisions of Course Preferences}

The analysis of the applications indicated extremely biased choices. Students tended to apply for courses close to their major and were not interested in courses far from their specialty. For example, the first course choice of $92 \%$ of the students belonging to the Department of Food Science and Nutrition of the School of Human Science and Environment was the course entitled Food Culture and Environment, while very few applied for natural science courses, which were less connected to their major. This bias was serious, especially in the category of Introduction to Research, where teachers give lectures about their own field for students from the other fields. The difference in the application rate by student's course was more than a factor of 3 in 18 classes.

Such biased choices are not desirable because the liberal arts educational policy is that students should have opportunities to learn subjects far from their own major. We explained this at the committee meeting. One possible solution is that a course close to a student's major would be considered a special subject instead of a liberal arts subject. Although the committee member understood the problem, the reform will be implemented next year because such a change needs to be thoroughly considered for consistency within the curriculum of each school. In ad- 
dition, the proposed solution conflicts with another policy of the general education, which states that the university should offer equal opportunity to all students regardless of school.

\subsection{Correlation between the preference order and grade point}

We found that the grade point has a weak dependence on the preference order. We analyzed the data of the subject Synchrotron Radiation Science through 2011 to 2015. This class was an omnibus lecture series, and the total score was a simple sum of the points independently given by five teachers. Thus, the teachers' personality or lecture style has a negligible bias. Figure 7 shows the average score as a function of registered students' preference order. It suggests that a student registered to an un-preferred subject is at a disadvantageous and should earn a lower grade.

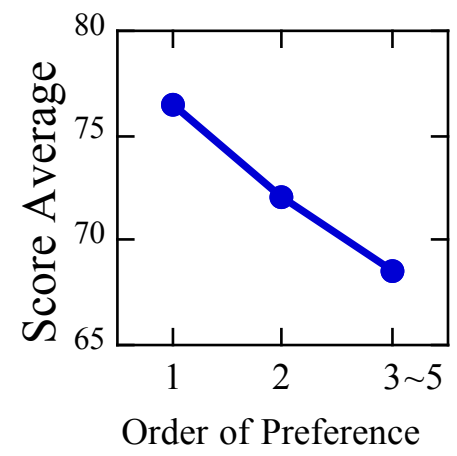

Figure 7: Relation between the grade point and the preference order.

Figure 8 provides more information on the distribution of each score. We thought that the difference between the groups with the first and second preference would be due to a strong or weak motivation. However, we cannot evaluate the distribution of the students with a preference order lower than the two due to the small sample size; the lowest average score was due to two students who score less than 20 who belonged to the School of Human Science and Environment and were less familiar with physics and mathematics. It was possible that their low scores reflect an inability to understand the course material. 


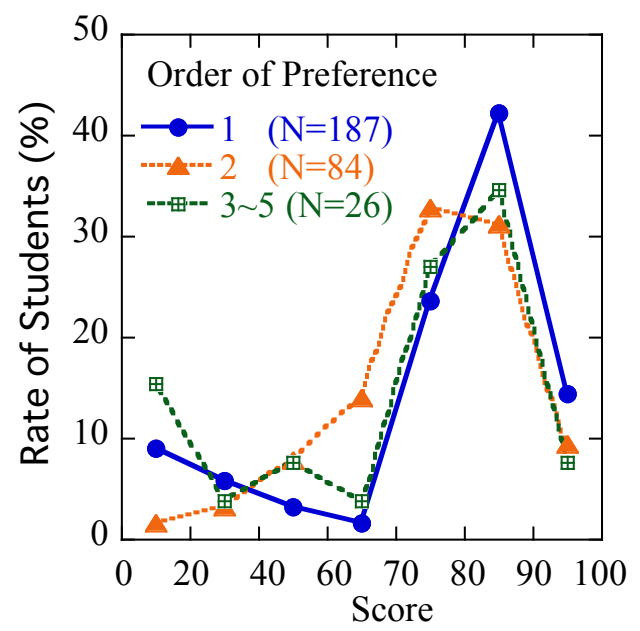

Figure 8: Distribution of grade points (full score $=100$ ) of students with different preference orders for Synchrotron Radiation Science from 2011 to 2015. $N$ denotes the number of students in the preference group.

\subsection{Instructional Problem}

We found one problem in the submission behavior of students from the Department of Electrical Engineering and Computer Science of the School of Engineering. In 2015, 30 out of 125 students submitted less than five courses for each category. Thus, these students are outliers. We think that there was a problem in explaining the submission instructions in this department. However, this problem was resolved in 2016.

Table 4: Number of students who submitted less than five subjects for each category. The numerator represents the number of students who submitted less than five subjects and the denominator is the total number of students.

\begin{tabular}{lll} 
School or Department & FY 2015 & FY 2016 \\
\hline \hline Department of Mechanical Engineering and Metallurgy & $2 / 129$ & $2 / 130$ \\
Department of Electrical Engineering and Computer Science & $\mathbf{3 0 / 1 2 5}$ & $3 / 127$ \\
Department of Applied Chemistry and Chemical Engineering & $1 / 102$ & $1 / 111$ \\
Department of Material Science & $1 / 88$ & $2 / 100$ \\
Department of Life Science & $1 / 85$ & $1 / 92$ \\
School of Human Science and Environment & $1 / 214$ & $2 / 213$ \\
\hline
\end{tabular}




\subsection{Effect of Additional Drawing Rules}

We investigated the implementation of additional drawing rules designed to equalize the chance of students registering for a preferred course. Still we have some students who blame the office for their lottery results. That claim on lottery is not common at other colleges because students who don't win the lottery will register to the class with higher priority the following year [14]. However at the western area of the University of Hyogo, students hardly register to their preferred class in the following year. Students from the School of Science or the School of Human Science and Environment have to move to different campuses in the second year. The other students from the School of Engineering did not have enough time for the liberal arts with their tight timetable in the second year.

As shown in Figure 5, most students registered for a high preference course in the spring semester. Thus, we focused on the lottery rules for the fall semester. We simulated the lottery process using the application data in 2015 for the fall semester with additional rules. We used the average of the order of the preference number over three categories by semester as an index. We did not evaluate the special categories for the School of Engineering.

One rule was that students unable to register for their first preference due to the lottery in the spring semester have first priority for the lottery in the fall and second priority for all non-lottery courses in the same category in the fall. With this new rule, the condition explained in the section 3.2 is automatically satisfied. Figure 8 shows the distribution of students in the spring index and fall index spaces. Figure 8 (a) is the original drawing result, which used a simple random scheme. Figure 8 (b) shows the result with the above rule. The new rule reduces the number of students with bad luck for both semesters.

The second additional rule was that every student is registered to at least one first preference course in the three categories. Without this rule, 33 students lost all three of the lotteries for the first preference subjects in the fall semester. The new rule would reduce number of students with the worst index as shown in Figure 8 (c). We set the additional rule only for the lottery concerning the first preference because changing rules for other lotteries is ineffective to improve the index. A student who lost the first lottery for the top choice tends to choose the other popular courses as the lower choices, which have no seat for lower preference. Therefore changing lottery rule for lower preferences is not effective to "save" him/her from registering for his/her fifth preference.

Table 5: Liberal Arts Subjects.

\begin{tabular}{lllll}
\hline $\begin{array}{c}\text { Semes- } \\
\text { ter }\end{array}$ & Category & $\begin{array}{l}\text { Social } \\
\text { Science }\end{array}$ & $\begin{array}{l}\text { Cultural } \\
\text { Science }\end{array}$ & $\begin{array}{l}\text { Introduction } \\
\text { to Research }\end{array}$ \\
\hline \multirow{4}{*}{ Spring } & Number of all subjects & 9 & 8 & 10 \\
& Number of fully occupied subjects & 2 & 4 & 2 \\
& Full capacity & 1090 & 840 & 1225 \\
\multirow{2}{*}{ Fall } & Number of all subjects & 7 & 8 & 10 \\
& Number of fully occupied subjects & 4 & 4 & 4
\end{tabular}



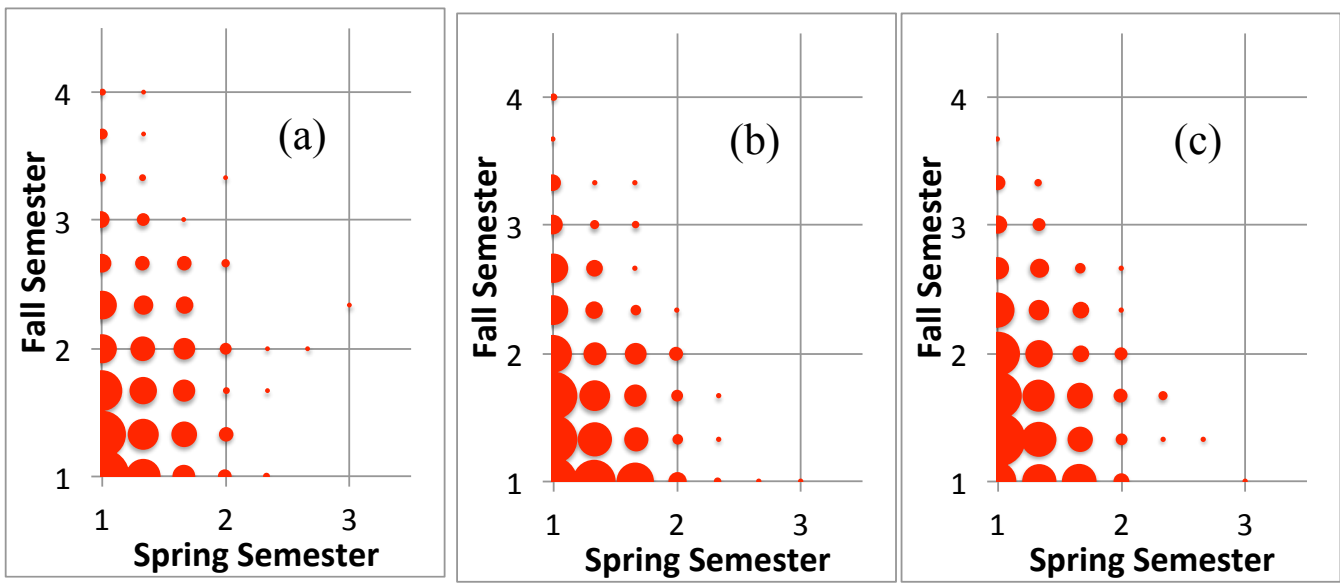

Figure 9: Distribution of students in the space of the preference index. The preference index is the average of the order of preference over three subject of each semester. Drawing rule (a) simply uses an independent random number. Drawing rule of (b) gives priority in the lottery for the fall semester to students who have a poor index for the spring semester. One more rule is added for (c) in which every student gets at least one registration to a first preference subject.

\section{Possible Improvement of Management}

Our experience identifies the following factors, which involve the PDCA cycle: (1) A high motivation is necessary to realize improvement. We, the IR section, took initiative in all phases except the Do phase, which was executed by the secretariats. Secretariats have difficulty with motivation and are less interested in executing the Check and Act phases due to the frequent personnel changes by the administrative office. This turnover also inhibits project continuance. To successfully implement this PDCA cycle, it is important for the IR section to be involved in most phases of the process. (2) Strong communication and buy-in of all stakeholders is imperative. We made close face-to-face contact with the officers, enabling an effective collaboration. In the Plan phase, we sometimes need to discuss innovative ideas such as the one to reduce the schedule from two weeks to four days. Without support of all parties, change would not be implemented. (3) We could take any role, if necessary. We had to serve as the technical adviser on the discussion on the OTR system. Thus, it was natural that we tried to train the secretariats to realize improvements in the process.

In order to understand process of data analysis, G.W. McLaughlin et al. identified five functions and three roles of information support [13]. However, we are not at a stage for that analysis. The narrow circular arcs in Figure 1 shows that we took most functions and roles in the improvement cycles. Our work in 2016 was much different from that in 2015 because there existed no standard in IR work of our university. The output results in 2016 had wide variations and some of them were not useful at that present. These all means that our IR is now at the ear- 
ly stage and we are trying to get trust by secretaries and the responsible person in the university organization. Actually we helped the secretary to solve one untold problem in class placement in 2016. Then we were requested to contribute more to the process in 2017. We hope that the conditions for an every year improvement are in place.

\section{Acknowledgement}

We thank Prof. Okuda at the School of Engineering, who was the chairman of the Committee of General Education in the Western Area. He understood our idea and provided faculty to implement our action before we entered the IR office. Without his leadership, we would not have even started this work.

\section{References}

[1] Public University Corporation of the University of Hyogo: English Home Page; http://www.u-hyogo.ac.jp/pdf/english.pdf.

[2] "Reform Action Plan to Articulate High Schools and Universities", Ministry of Education, Culture, Sports, Science and Technology, japan; http://www.mext.go.jp/en/news/topics/detail/1372626.htm.

[3] “PDCA Cycle": https://en.wikipedia.org/wiki/PDCA.

[4] The Deming Institute: Home Page; https://www.deming.org.

[5] Howard S. and Gitlow, Shelly J. Gitlow, (1987)."The Deming guide to quality and competitive position", 1987, Englewood Clifts, NJ: Prentice-Hall, Inc.

[6] Ronald Moen, and Clifford Norman, "Evolution of the PDCA Cycle", 2006; http://pkpinc.com/files/NA01MoenNormanFullpaper.pdf.

[7] W.E. Deming, "To Management", translated into English by John Dowd, http://www.jsdstat.com/Statblog/wp-includes/Hakone.pdf.

[8] "University Accreditation Handbook," Japan University Accreditation Association; http://www.juaa.or.jp/en/images/accreditation/handbook_university.pdf.

[9] M. Pietrzak and J. Paliszkiewicz, "Framework of Strategic Learning: The pdca cle,“ Management 10 (2): 149-161, cc by-nc-nd 4.0, 2015.

[10] C. BaoQuan, H. ZhenHai, Z. EnHui, and W. GuiRong, "Education Management, Education Theory \& Education Application", AISC 109, Ed. By Y. Wang. Springer-Verlag Berlin Heidelberg, 2011, pp.367-370.

[11] S. Rita, and K. Lakshmi, "Mechanics of How to Apply Deming's PDCA Cycle to Management Education," 2009; http://ssrn.com/abstract=1353763.

[12] Rr. Sri Kartikowati, "The Technique of "Plan Do Check and Act" to Improve Trainee 
Teachers' Skills,” Asian Social Science; Vol. 9, No. 12; 2013.

[13] G.W. McLaughlin, R.D. Howard, L.A. Balkan, and E.W. Blythe, "People, Processes, and Managing Data. Resources in Institutional Research, No. 11", 1998, Association for Institutional Research, 114 Stone Building Florida State University, Tallahassee, FL 32306-4462; http://files.eric.ed.gov/fulltext/ED437887.pdf.

[14] The College Buzz Book, Edited by Carolyn C. Wise \& Stephanie Hauser and the staff at VAULT, Drexel University ONLINE, 2007 edition, Drexel University ONLINE, p.167 (Yale University), p.365 (Boston University), p.368 (Brndeis University), and p.378 (Harvard University). 